\title{
miR-141 inhibits glioma vasculogenic mimicry by controlling EphA2 expression
}

\author{
GUOXIONG LI ${ }^{1,2}$, MIN HUANG ${ }^{2}$, YINGQIAN CAI ${ }^{2}$, YIQUAN KE ${ }^{2}$, YUANTAO YANG ${ }^{2}$ and XINLIN SUN ${ }^{2}$ \\ ${ }^{1}$ Department of Neurosurgery, People's Hospital of Shiyan, Shenzhen, Guangdong 518108; ${ }^{2}$ Department of Neurosurgery, \\ Zhujiang Hospital, Southern Medical University, The National Key Clinical Specialty, The Engineering Technology \\ Research Center of Education Ministry of China, Guangdong Provincial Key Laboratory on Brain \\ Function Repair and Regeneration, Guangzhou, Guangdong 510280, P.R. China
}

Received December 1, 2017; Accepted May 3, 2018

DOI: $10.3892 / \mathrm{mmr} .2018 .9108$

\begin{abstract}
Human glioma is a pernicious tumor from the central nervous system; it has been reported that microRNAs (miRs) may have carcinogenic or tumor suppressor effects on human glioma. The aim of the present study was to assess miR-141 expression and functional role in human primary glioma, as well as in tumor-derived cell lines. The expression of miR-141 in primary human glioma tissues and cell lines was assessed by employing reverse transcription-quantitative polymerase chain reaction. Next, its role in cellular growth, migration, invasion and vasculogenic mimicry (VM) regulation was determined using various in vitro and in vivo assays, and on the identification its target gene(s) using luciferase assays. The results demonstrated that miR-141 expression was downregulated, and Ephrin type-A receptor 2 (EphA2) was upregulated in the primary human gliomas and human glioma-derived cell lines tested. In addition, a negative correlation existed between miR-141 and EphA2 expression levels in glioma grades II, III and IV. Furthermore, exogenous miR-141 expression resulted in decreased proliferation, migration and invasion, as well as in apoptosis and cell cycle arrest in vitro. It was also revealed that exogenous miR-141 expression resulted in in vivo inhibition of tumor growth and inhibition of the development of VM. Finally, the present study successfully confirmed that EphA2 was a direct target of miR-141 in glioma-derived cells using luciferase assays. Based on these results, it was concluded that miR-141 may regulate cell proliferation, migration, invasion
\end{abstract}

Correspondence to: Professor Yiquan Ke, Department of Neurosurgery, Zhujiang Hospital, Southern Medical University, The National Key Clinical Specialty, The Engineering Technology Research Center of Education Ministry of China, Guangdong Provincial Key Laboratory on Brain Function Repair and Regeneration, 253 Gongye Road, Guangzhou, Guangdong 510280, P.R. China

E-mail:kyquan@smu.edu.cn

Key words: glioma, microRNA-141, Ephrin type-A receptor 2, vasculogenic mimicry, migration, invasion and VM formation by controlling EphA2 expression; also, its target EphA2 may be a novel diagnostic/prognostic biomarker and a potential anti-VM therapeutic target.

\section{Introduction}

Glioma is a pernicious tumor in the central nervous system. At present, about $70 \%$ of all brain tumors results from glioma each year (1). The patients' survival rates strongly depend upon the tumors' histological grades. Patients afflicted with this serious malignant form survive on average less than one year (2). Although progress has been made in surgery, radiotherapy and chemotherapy regimens, the prognosis of patients with glioma is still poor because of its fast and invasive growth, its genetic heterogeneity, and our poor understanding on its underlying molecular mechanisms (3). Researchers are working on new treatments. $(4,5)$. The previous research confirmed that VM is related with tumor blood supply and metastasis (6). In glioma, the VM positive rate resulted from the glioma's grades and responsible of poor prognosis, the glioblastoma (GBM) (grade IV of glioma) has the strongest ability of VM formation. As a novel blood supply's form, the inhibition of VM could serve as an alternative therapeutic target for gliomas (7). Along these years, it's the vascular-targeted therapy that has gradually been more and more accepted.

MicroRNAs (miRNAs), which are approximately 22 nucleotide-long RNAs without coding endogenous can regulate gene expression of target at post-transcriptional level. They can bind with the 3'-untranslated regions (3'-UTRs) of mRNAs and, by doing so, repress their translation or cause their degradation $(8,9)$. Anomalous miRNA expression has been found to have some effects on the developing process of a wide range of tumors and, as such, miRNAs may be used for their diagnosis, prognosis and treatment $(10,11)$. Various miR-200 family members, i.e., miR-141, 200c, 200b, 200a and 429, have been reported to play important roles in a variety of cancers $(12,13)$, including proliferation, invasion and apoptosis $(14,15)$. But, so far, the expression and function of miR-141 in the developing process of human glioma has remained unclear. EphA2 gene belongs to the ephrin receptor subfamily of the protein-tyrosine kinase family, it has been involved in mediating the development of events, especially in the nervous system (16). 
Here, the expression of miR-141 in primary human glioma tissues and glioma-derived cell lines was studied, also with the effect of exogenous miR-141 expression on glioma tumor progression, including cell proliferation, migration, invasion and vasculogenic mimicry ( $\mathrm{VM}$ ) both in vitro and in vivo. By using a luciferase reporter assay, direct interactions between miR-141 and the 3'UTR of its predicted target EphA2 were assessed.

\section{Materials and methods}

Clinical samples. The normal brain tissues samples came from intracranial trauma cranial decompression surgery, and glioma tissues samples came from the pathologic glioma surgeries. Cases inclusion/exclusion criteria: i) patients underwent surgical treatment, without radiotherapy and chemotherapy before surgery; ii) postoperative pathology was diagnosed as glioblastoma, and iii) complete patient information can be obtained. All glioma samples were classified to 4 grades, according to criteria from the World Health Organization (WHO): Primary grade pilocytic astrocytoma (WHO I), grade II astrocytoma (WHO II), grade III anaplastic astrocytoma (WHO III) and grade IV glioblastoma multiforme (WHO IV). Ten normal brain tissue samples and forty primary glioma tissue samples were selected for this study. Of each grade 10 cases were included. All samples were freshly frozen in liquid nitrogen and then stored at $-80^{\circ} \mathrm{C}$ until RNA extraction. At the same time, this research work was permitted by the Institutional Review Boards of Southern Medical University and the Zhujiang Hospital, and all participants provided written informed consent.

Immunohistochemical assay. The glioma tissues and normal brain tissues were fixed for $1 \mathrm{~h}$ in $4 \%$ paraformaldehyde in phosphate buffered saline (PBS), and sliced into 3-5 $\mu \mathrm{m}$ sections. Then operated the deparaffinization and hydration, which means the slides were treated with peroxide after blocked by serum (Invitrogen; Thermo Fisher Scientific, Inc., Waltham, MA, USA). The anti-EphA2 antibodies (ab78002; Abcam, Cambridge, MA, USA) were added and incubated overnight. After washed for five times with PBS, the slides were added and incubated for $30 \mathrm{~min}$ at $37^{\circ} \mathrm{C}$ with diaminobenzidine (DAB) solution (secondary antibody: HRP conjugated goat anti-rabbit antibody). At last, the lightly counterstained process with hematoxylin, dehydrated process and mounted process were treated on these slides, respectively. Visual analysis was performed with Olympus fluorescence microscope (CX71; Olympus Corporation, Tokyo, Japan).

Cell culture and transfection. The GBM cell lines (A172, code: TCHu171 cell and U251, code: TCHu 58 cell) and the normal glial cell line (HEB cell) were obtained from Shanghai Cell Collection (http://www.cellbank.org.cn/, Shanghai, China). The cells' culture condition was: $10 \%$ fetal bovine serum (FBS) in Dulbecco's modified Eagle's medium (DMEM) and at $37^{\circ} \mathrm{C}$ in a $5 \% \mathrm{CO}_{2}$ humidified atmosphere. All cells were harvested in their log phase. miRNAs were bought from GenePharm (Shanghai, China) and then transfected into the cells using a Lipofectamine 2000 transfection reagent (Invitrogen, Carlsbad, CA, USA) by following the protocol in manuals. The respective miRNA sequences are listed in Table I. After transfection, reverse transcription-quantitative polymerase chain reaction (RT-qPCR; $48 \mathrm{~h}$ after transfection) and western blotting ( $72 \mathrm{~h}$ after transfection) analyses were employed to assess these transfection efficiencies.

Assay of cell viability. The A172 and U251 cells transfected were seeded in 96-wells plates $\left(1 \times 10^{3}\right.$ cells/well) in triplicate and incubated. After this incubation, a 3-(4,5-dimethyl-2-thiazolyl)-2, 5-diphenyl-2-H-tetrazolium bromide (MTT) working solution was added into the medium after which the cells were incubated for another $4 \mathrm{~h}$. Next, the medium was discarded and dimethyl sulphoxide (DMSO) $(150 \mu \mathrm{l})$ was added in order to dissolve the formazan crystals. Cell viabilities were evaluated at 24, 48 and $72 \mathrm{~h}$ by measuring the $490 \mathrm{~nm}$ absorbance by employing a microplate reader (Bio-Rad 680 Microplate Reader; Bio-Rad Laboratories, Inc., Hercules, CA, USA). The assays were repeated thrice.

Wound healing assay. Transfected A172 and U251 cells $\left(1 \times 10^{6}\right.$ cells/well) were seeded into 6 -well plates and up to confluence during 24-48 h. Next, cells from each well were divided into 2-3 grids. After attachment, artificial, homogenous wounds were created by scratching the monolayers with $200 \mu \mathrm{l}$ pipette tips and washed the cells for twice with serum-free medium. Next, the cells continued culturing in medium with serum-free for another $24 \mathrm{~h}$. Once a wound was inflicted and after $24 \mathrm{~h}$, microscopic images of the same area were immediately captured. Finally, the following formula was employed to calculate the cell migration distances: (migration distance=initial distance-final distance).

Transwell invasion assay. Transfected A172 and U251 cells were resuspended in medium with serum-free until a density of $5 \times 10^{5}$ cells $/ \mathrm{ml}$. Three hundred microliters of these cell suspension were harvested and added into the upper chamber of each well containing a 24-well polycarbonate Transwell membrane insert (BD Biosciences, Franklin Lakes, NJ, USA) and coated with $30 \mathrm{mg} / \mathrm{cm}^{2}$ matrigel (Sigma-Aldrich; Merck KGaA, Darmstadt, Germany). After incubation for $24 \mathrm{~h}$ at $37^{\circ} \mathrm{C}$, and cells on the upper membrane surface were gently removed with a cotton swab. Next, fixed the filters for $30 \mathrm{~min}$ in $95 \%$ ethanol and stained for 30 min with a $0.2 \%$ crystal violet solution, after which the cells that invaded the matrigel and adhered to the lower surface of the filter were counted (five high-power fields per chamber) using an inverted microscope.

Cell cycle assay. Transfected A172 and U251 cells were collected, washed by PBS and fixed for $12 \mathrm{~h}$ in $70 \%$ ethanol at $4^{\circ} \mathrm{C}$. After washing by PBS, $2 \times 10^{6}$ cells were added and incubated for $30 \mathrm{~min}$ with the DNA-binding dye propidium iodide $(\mathrm{PI}, 50 \mu \mathrm{g} / \mathrm{ml})$ and RNase $(1.0 \mathrm{mg} / \mathrm{ml})$ at $37^{\circ} \mathrm{C}$ in dark. At last, the cells were washed and red fluorescence was readed and analyzed by a flow cytometer (Accuri ${ }^{\mathrm{TM}}$ C6; BD Biosciences). The cell cycle analyses were performed in triplicate and repeated thrice.

Apoptosis assay. Apoptosis was determined by an FITC Annexin V apoptosis detection kit (556547; BD Biosciences) by following the manufacturer's instructions. Briefly, collected cells $48 \mathrm{~h}$ after transfection, washed twice in PBS and 
Table I. Sequences of the microRNA-141 mimic and microRNA-Negative Control mimic control.

\begin{tabular}{lcl}
\hline Genes & Names & \multicolumn{1}{c}{ Primers (5' to 3') } \\
\hline miR-141 & miR-141 mimic & $\begin{array}{l}\text { UAACACUGUCUGGUA } \\
\text { AAGAUGG }\end{array}$ \\
Mimic control & miR-141-NC & $\begin{array}{l}\text { GGGAGUGAAGACACG } \\
\text { GAGCCAGA }\end{array}$ \\
& & \\
\hline
\end{tabular}

The miRNA-141 sequence was obtained from miRbase (www. mirbase.org/). The miRNA mimic and control were designed and synthesized by GenePharma Co., Ltd. miR, microRNA; NC, negative control.

re-suspended in binding buffer with a density of $1 \times 10^{3}$ cells $/ \mathrm{ml}$. Next, the cells were simultaneously incubated for $20 \mathrm{~min}$ with FITC-labeled Annexin V and PI and analyzed by a flow cytometer (Accuri ${ }^{\mathrm{TM}}$ C6; BD Biosciences).

$R N A$ extraction and RT-qPCR. Total RNA from $2 \times 10^{6}$ glioma cells was extracted by operating TRIzol reagent (Invitrogen; Thermo Fisher Scientific, Inc.) after which a cDNA Synthesis Kit was used to synthesize cDNA by following the manufacturer's instructions (Takara Biotechnology Co., Ltd., Dalian, China). RT-qPCR was performed to assess miRNA and mRNA expression levels using a LightCycler 480 detection system (Roche Diagnostics, Indianapolis, IN, USA) and SYBR-Green dye. The primers used are shown in Table II. $\beta$-actin mRNA and U6 snRNA levels were employed for normalization. DNA was amplified with an initial denaturation at $95^{\circ} \mathrm{C}$ for $3 \mathrm{~min}$, followed by 45 cycles of $95^{\circ} \mathrm{C}$ for $20 \mathrm{sec}$ and $60^{\circ} \mathrm{C}$ for $1 \mathrm{~min}$. RT-qPCR data were used to analyze and express as relative mRNA or miRNA levels by CT values and then subsequently convert to fold changes.

Western blot analysis. $2 \times 10^{6}$ cells were lysed by a radioimmunoprecipitation assay buffer which contains a protease inhibitor cocktail (Roche Diagnostics) using standard procedures. Proteins' concentrations were measured by using a Micro BCA protein assay kit (Pierce; Thermo Fisher Scientific, Inc.). Total cell lysates $(50 \mu \mathrm{g})$ were loaded in each lane and resolved by sodium dodecyl sulfate-polyacrylamide gel electrophoresis (SDS-PAGE; Invitrogen; Thermo Fisher Scientific, Inc.), and then transferred to polyvinylidene difluoride (PVDF) membranes. The PVDF membranes were blocked with $7 \%$ non-fat milk for $1 \mathrm{~h}$ at $37^{\circ} \mathrm{C}$, followed by immunoblot detection and visualization with ECL western blotting detection reagents (Pierce; Thermo Fisher Scientific, Inc.). Immunoblotting was performed using anti-EphA2 antibodies (ab185156, dilution: 1/1,000; Abcam), anti-Bax antibodies (ab32503, dilution: 1/1,000; Abcam) and anti-Bcl-2 antibodies (ab32124, dilution: 1/1,000; Abcam) at $37^{\circ} \mathrm{C}$ for $2 \mathrm{~h}$ respectively, followed by incubation with the appropriate horseradishperoxidase-conjugated IgG secondary antibodies (ab97023, dilution: 1/5,000; Abcam) for $1 \mathrm{~h}$ at room temperature. GAPDH (ab8245, dilution: 1/1,000; Abcam) levels were used for normalization. The protein bands were scanned and
Table II. Primers used in the present study.

\begin{tabular}{|c|c|c|}
\hline Genes & Names & Primers ( $5^{\prime}$ to $\left.3^{\prime}\right)$ \\
\hline \multirow[t]{5}{*}{ miR-141 } & miR-141-RT & GTCGTATCCAGTGCGTGTCGT \\
\hline & & GGAGTCGGCAATTGCACTGGA \\
\hline & & TACGACTCCAACA \\
\hline & miR-141-F & GGCATCTTCCAGTACAGTGT \\
\hline & miR-141-R & CAGTGCGTGTCGTGGAGT \\
\hline \multirow[t]{5}{*}{ U6 } & U6-RT & GTCGTATCCAGTGCAGGGTCC \\
\hline & & GAGGTATTCGCACTGGATACG \\
\hline & & ACAAAAAT \\
\hline & U6-F & CAAATTCGTGAAGCGTTCCATA \\
\hline & U6-R & AGTGCAGGGTCCGAGGTATTC \\
\hline \multirow[t]{2}{*}{ EphA2 } & EphA2-F & GCCCCACATGAACTACACCT \\
\hline & EphA2-R & GGCTCTGTCTGGTTGATGCT \\
\hline \multirow[t]{2}{*}{$\beta$-actin } & $\beta$-actin-F & CCTGTACGCCAACACAGTGC \\
\hline & $\beta$-actin-R & ATACTCCTGCTTGCTGATCC \\
\hline
\end{tabular}

Primers were designed using the Primer Express version 2.0 software tool. The primer specificities were confirmed using the Primer-BLAST web software tool (NCBI, USA). miR, microRNA; F, forward; R, reverse; RT, reverse transcription; EphA2, Ephrin type-A receptor 2.

quantified using a ChemiDoc image analysis system (Bio-Rad Laboratories, Inc.).

Luciferase assay. Wild-type and mutant EphA2 3'UTR reporter and control constructs were bought and obtained from Shanghai GeneChem (Shanghai, China). For dual luciferase assays, $150 \mathrm{nM}$ pre-miR-141 or a negative precursor control were transfected into $5 \times 10^{5}$ cells by employing Lipofectamine 2000 (Invitrogen; Thermo Fisher Scientific, Inc.). After $24 \mathrm{~h}$, both Renilla luciferase reporter $(0.35 \mathrm{ng})$ and firefly luciferase reporter $(1.5 \mathrm{mg})$ were simultaneously transfected into cells in 24-well plates. After $24 \mathrm{~h}$, firefly luciferase activities were detected by employing a dual luciferase reporter assay kit (Promega Corporation, Madison, WI, USA), whose results were normalized into Renilla luciferase activities by following the manual's protocol.

In vivo xenografting. Male Fisher 344 rats weighing 200-220 g were obtained from the Animal Research Center, which belongs to Southern Medical University, China, and vthen divided randomly into 2 groups (four rats per group). The rats were maintained on a $12 \mathrm{~h}$ light/12 h dark cycle under room temperature $\left(23 \pm 1^{\circ} \mathrm{C}\right)$ and humidity $(55 \pm 5 \%)$ and fed with standard forage and clean water. miR-141 and miR-NC sequences were inserted into a pcDNA6.2-GW/EmGFP-miR vector. After transfection into A172 cells, positive clones were selected using $1 \mu \mathrm{g} / \mathrm{ml}$ puromycin and propagated further. After verification of miR-141 expression, the stably transfected cells were suspended in $5 \mu \mathrm{l}$ medium with serum-free $\left(2 \times 10^{8}\right.$ cells $\left./ \mathrm{ml}\right)$ and intracranially injected into the rats as Yang et al (17), report in 2012, with a few difference. Briefly, 3.5\% (w/v) chloral hydrate $(10 \mathrm{ml} / \mathrm{kg})$ anesthetized into animals and put in sterile conditions. Aseptic surgical techniques were used to perform a midline incision and to open the scalp to expose the frontal and 

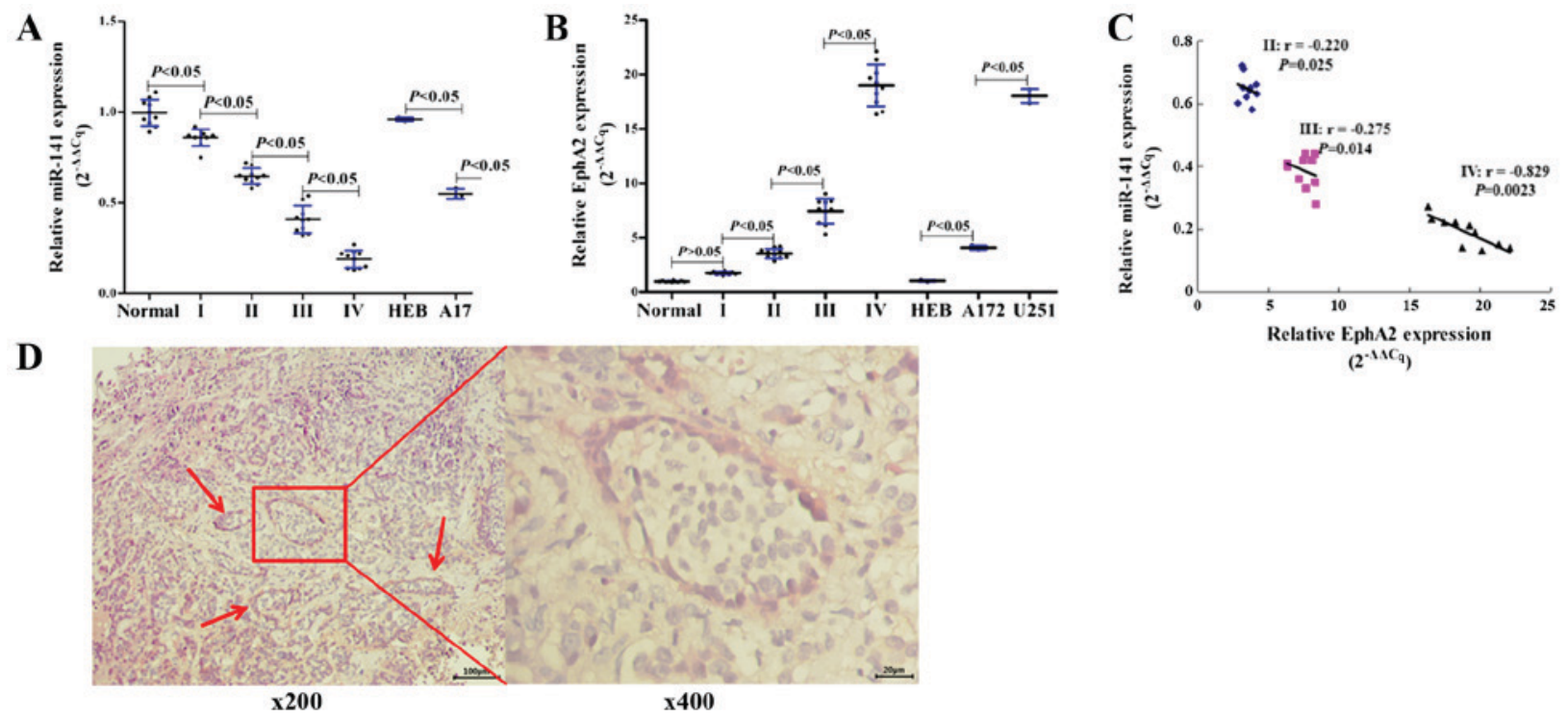

$\left(2^{-14 C_{9}}\right)$

Figure 1. Expression of miR-141 and EphA2 in primary glioma tissue samples, and HEB, A172 and U251 cells. (A) miR-141 expression analyzed by RT-qPCR in glioma tissues and cell lines. (B) EphA2 expression analyzed by RT-qPCR in glioma tissues and cell lines. (C) Negative correlations between EphA2 with miR-141 in glioma tissues. (D) Immunohistochemistry images of EphA2 in the glioma tissues (magnification, x200 and x400). The glioma grade was determined according to World Health Organization criteria. The relative expression level of miR-141 is presented as the ratio of the expression level of U6. The relative expression of EphA2 is presented as the ratio of the expression level of $\beta$-actin. miR, microRNA; EphA2, Ephrin type-A receptor 2; RT-qPCR, reverse transcription-quantitative polymerase chain reaction.

temporalis bones. A burr hole was generated through the skull at an appropriate location $(2.0 \mathrm{~mm}$ posterior to the bregma and $1.0 \mathrm{~mm}$ right to the midline) without breaking the dura. Next, a 26-gauge needle was inserted $3.0 \mathrm{~mm}$ ventral to the dura and retreated $0.5 \mathrm{~mm}$, after which the cells were implanted using a $10-\mu 1$ micro-syringe at an infusion rate of $1 \mu \mathrm{l} / \mathrm{min}$. A total of $2 \times 10^{5}$ cells were inoculated into the brain. After the infusion, the needle was kept in place for $10 \mathrm{~min}$ (in order to balance the pressure of the cranial vault). Next, removed needle slowly, and immediately sealed the hole with sterile bone-wax to prevent the solution from leaking. Finally, the animals were returned to the animal care facilities. The rats were given a daily physical examination. After 3 weeks (determined in a preliminary experiment), the rats were anesthetized using $1 \%$ sodium pentobarbital ( $40 \mathrm{mg} / \mathrm{kg}$ per rat), and then were sacrificed by exsanguination. The tumor samples were carefully removed and weighed. Western blotting was employed and operated to determine the apoptosis-related proteins' expression.

Assay of VM. VM experiments followed the Li et al (18) report, in 2014, in vitro, with a few modifications. Briefly, $50 \mu 1$ ECM matrigel (Sigma-Aldrich; Merck KGaA) was added and dropped onto $18 \mathrm{~mm}$ glass coverslips in 6-well plates and incubated for $1 \mathrm{~h}$ at $37^{\circ} \mathrm{C}$. Next, A172 and U251 cells transfected with miR-141 mimic and miR-NC were seeded onto the coverslips coated. After incubation for 24-48 h, the development of VM was evaluated by periodic acid-Schiff (PAS) staining. To this end, the cells were fixed for $10 \mathrm{~min}$ in $4 \%$ paraformaldehyde in PBS, oxidized for $5 \mathrm{~min}$ in a $0.5 \%$ periodic acid solution, washing with PBS, and placed for $15 \mathrm{~min}$ in Schiff reagent, after which the coverslips were immediately rinsed with PBS. Finally, dried the coverslips at room temperature and the PAS signals were imaged at a $400 \mathrm{x}$ magnification. In vivo, the glioma tumor tissues were sliced into 3-5 $\mu \mathrm{m}$ sections, and the following steps of PAS staining as previously.

Statistical analyses. SPSS v17.0 statistical analysis software (SPSS, Inc., Chicago, IL, USA) was employed for the statistical analyses. The significance of the differences was determined by Student's t-test, or one-way analysis of variance with the least significant difference post hoc test when equal variances were assumed or with Dunnett's T3 post hoc test when equal variances were not assumed. The data are presented as the mean \pm standard error mean and $\mathrm{P}<0.05$ was considered to indicate a statistically significant difference.

\section{Results}

miR-141 is downregulated and EphA2 is upregulated in human glioma tissues and cell lines. The expression of miR-141 was assessed using RT-qPCR in normal brain tissues, primary glioma tissues, and glioma- and normal glia-derived cell lines. We found that miR-141 was at relatively high levels expression in normal brain tissues, whereas its expression was significantly $(\mathrm{P}<0.05)$ downregulated in the glioma samples (grades I, II, III and IV; Fig. 1A). In addition, we also found that the miR-141's expression steadily decreased as the glioma grades increased, and the expression of miR-141 was also found down regulation in the glioma-derived cell lines A172 and U251 (Fig. 1A). In contrast, we found that its putative target EphA2 was at relatively low levels expression in normal brain tissues, and whose expression was significantly $(\mathrm{P}<0.05)$ upregulated in glioma samples (grades I, II, III and IV). We also found that the EphA2 expression steadily increased as the glioma grades increased. EphA2 expression was also found to be up-regulated in the glioma-derived cell lines A172 and U251 (Fig. 1B). Furthermore, a Pearson correlation assay 

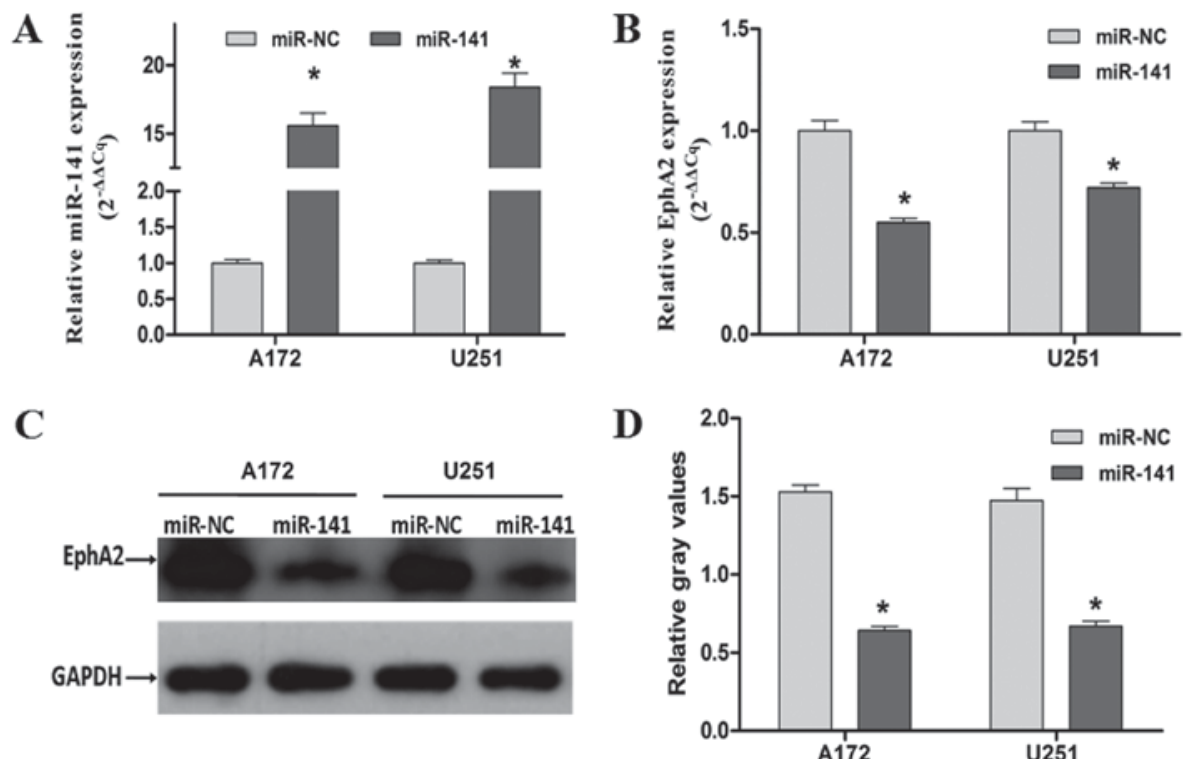

Figure 2. Expression of miR-141 and EphA2 in glioma-derived cells following transfection. (A) Expression levels of miR-141 and (B) EphA2 in A172 and U251 cells. (C) Western blotting analysis of EphA2 expression. (D) The relative gray values of EphA2 in A172 and U251 cells. The data are presented as the mean \pm standard error mean $(n=3)$. Each bar represents the mean of three independent experiments performed in triplicate. " $\mathrm{P}<0.05 \mathrm{vs}$. miR-NC group. miR, microRNA; EphA2, Ephrin type-A receptor 2; NC, negative control.

also indicated that a negative correlation existed in between miR-141 and EphA2 expression levels in glioma grades II, III and IV (Fig. 1C). In addition, immunohistochemical assay showed (Fig. 1D) that glioma grade IV tissue forms the typical VM, and EphA2 was expressed in the epidermis of VM vessel. We inferred from these results that there may be some sort of regulation relationship between miR-141 and EphA1 in glioma.

Exogenous miR-141 expression inhibits glioma cell proliferation, migration and invasion in vitro. To study the miR-141's functional role and its relationship with EphA2 in human glioma, A172 and U251 cells were transiently transfected with either a miR-141 mimic or a control mimic (miR-NC) (Table II). Using RT-qPCR, we found that compared with the control miR-NC transfected cells, the miR-141's expression was significantly upregulated in the miR-141 mimic transfected cells $(\mathrm{P}<0.05$; Fig. 2A). Moreover, we found that in the miR-141 mimic transfected cells the expression of EphA2 (see below) was significantly downregulated (Fig. 2B-D, P<0.05) by RT-qPCR and western blotting analyses (Fig. $2 \mathrm{C}$ and $\mathrm{D}, \mathrm{P}<0.05$ ).

We also found that miR-141's exogenous overexpression led to decreases in A172 and U251 cell proliferation using cell viability assay $(\mathrm{P}<0.05$; Fig. $3 \mathrm{~A}$ and $\mathrm{B})$ and migration using wound healing assays $(\mathrm{P}<0.05$; Fig. $3 \mathrm{C}$ and $\mathrm{D})$. An in vitro transwell invasion assay was subsequently employed to examine the invasive capacities of these cells. By doing so, we found that the invasive capacities were markedly reduced in the A172 and U251 cells with miR-141 mimic transfected, i.e., by 42.1 and $55.2 \%$, respectively $(\mathrm{P}<0.05$; Fig. $3 \mathrm{E}$ and $\mathrm{F})$. Based on these results, we conclude that miR-141's overexpression results in in vitro inhibition of the proliferation, migration and invasion of human glioma-derived cells.

miR-141 induces glioma cell apoptosis and cell cycle arrest in vitro. Next, we set out to assess the effect of miR-141 on the regulation of apoptosis and cell cycle progression using A172 and U251 cells which were transfected with either the miR-141 mimic or the control miR-NC mimic. By doing so, we found that the apoptotic rates increased in the cells with miR-141 transfected (19.1\% in A172 cells and $17.8 \%$ in U251 cells; Fig. 4A). Subsequent cell cycle analyses revealed that miR-141 mimic transfected cells were arrested at G2/M phase, i.e., the percentages of $\mathrm{G} 2 / \mathrm{M}$ phase cells were found to be 23.48 and $26.61 \%$ for the miR-141 transfected A172 and U251 cells, respectively, while the percentages were 1.34 and $7.87 \%$, respectively, in the miR-NC group $(\mathrm{P}<0.05$; Fig. 4B). Our additional observation of the pro-apoptotic protein Bax's up-regulation and the anti-apoptotic protein Bcl-2's down-regulation in the cells with miR-141 transfected underscores the notion that miR-141 overexpression induces apoptosis in glioma-derived cells (Fig. 4C and D).

EphA2 is a direct target of miR-141 in glioma cells. We used the miRecords resource (19) to identify potential miR-141 targets from three independent prediction tools included on the NCBI website. Among the putative miR-141 targets identified, we selected EphA2 for further analysis since the EphA2 3'UTR contains seven miR-141 potential binding sites (Fig. 5A) and since EphA2 has previously been implicated in tumor development. Next, an assay of luciferase reporter was performed to obtain direct evidence that EphA2 serves as a miR-141's genuine target in glioma cells. By doing so, compared to those co-transfected with the miR-NC control mimic, we found that cells simultaneously transfected with both the wild-type reporter and the miR-141 mimic showed a significant decrease in relative luciferase activity $(\mathrm{P}<0.05$; Fig. 5B). However, the cells transfected with both the mutant reporter and the miR-141 mimic did not show any effect on the reporter luciferase activity $(\mathrm{P}<0.05)$. Based on these data, a conclusion can be made that EphA2 indeed serves as a direct target of miR-141 in glioma-derived cells. 

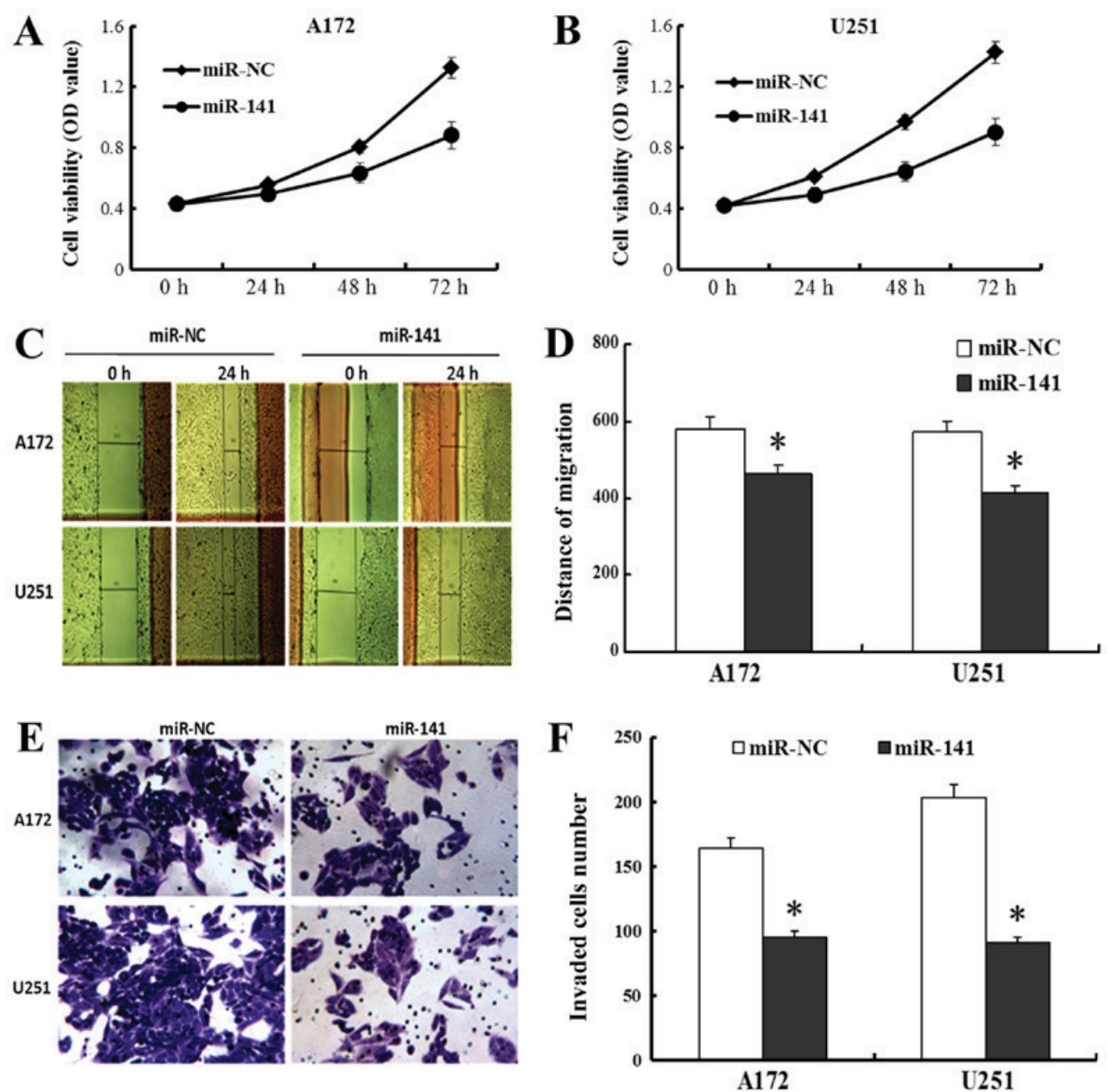

Figure 3. Exogenous miR-141 expression inhibits glioma cell proliferation, migration and invasion in vitro. A172 and U251 cells were transfected with miR-141 mimics or miR-NC control mimics.miR-141 inhibits glioma-derived cell proliferation in (A) A172 and (B) U251 cells. (C) miR-141 inhibits glioma-derived cell (D) migration (magnification, $x 40$ ). (E) miR-141 inhibits glioma-derived cell (F) invasion (magnification, $x 200$ ). The data are presented as mean \pm standard error mean $(n=3)$. Each bar represents the mean of three independent experiments performed in triplicate. ${ }^{*} \mathrm{P}<0.05$ vs. miR-NC group. miR, microRNA; NC, negative control.

miR-141 suppresses tumorigenesis in vivo. Stable miR-141 mimic transfected and miR-NC control mimic transfected A172 cells were injected intracranially into rats, after which tumor growth was evaluated. We found that the tumor weights in the miR-141 mimic group were significantly much lower than those in the miR-NC group $(\mathrm{P}<0.05$; Fig. $6 \mathrm{~A}$ and $\mathrm{B})$. Additional western blotting analyses of the resulting tumors showed that the EphA2 expression levels were also decreased in the miR-141 mimic groups. In addition, we found that the pro-apoptotic protein Bax expression levels were increased and that the anti-apoptotic protein $\mathrm{Bcl}-2$ expression levels were decreased in the miR-141 mimic groups in vivo (Fig. 6C and D). These data indicate that the apoptotic rates of the miR-141 mimic groups are increased and, thus, that exogenous miR-141 overexpression in glioma-derived cells induces apoptosis and suppresses tumorigenesis in vivo.

miR-141 suppresses the development of VM in vivo and in vitro. VM is related with tumor blood supply and metastasis. The number of vessels (nodes) and the remodeling of the microcirculation are used as histological markers of tumor progression. Cancers require adequate blood supply for in vivo growth, and VM serves an alternative pathway for maintaining this supply. Here, we calculated and analyzed the vessel numbers of the network channels, which reflect VM development. We found that A172 and U251 cells, whose levels of EphA2 are very high, and formed classical VM networks on matrigel in vitro. After the A172 and U251 cells transient transfection with miR-141 mimics, and a concomitant down-regulation of EphA2, we found that the number of vessels decreased from $9.67 \pm 0.58$ in the miR-NC mimic transfected cells to $5.33 \pm 0.58$ in the miR-141 mimic transfected cells (Fig. 7A). In vivo, the tumor tissue, which stably transfected with miR-141, formed classical VM vessels, compared with miR-NC group (Fig. 7B). Combined with the data obtained above, we conclude that miR-141 may be a regulatory genes, and EphA2 may be a direct regulator for the development of VM in glioma.

\section{Discussion}

By using both western blotting and RT-qPCR, we known that both the miR-141 and EphA2 expression levels were inversely correlated in the primary glioma tissues and glioma-derived cell lines tested. Based on this observation, we hypothesized 

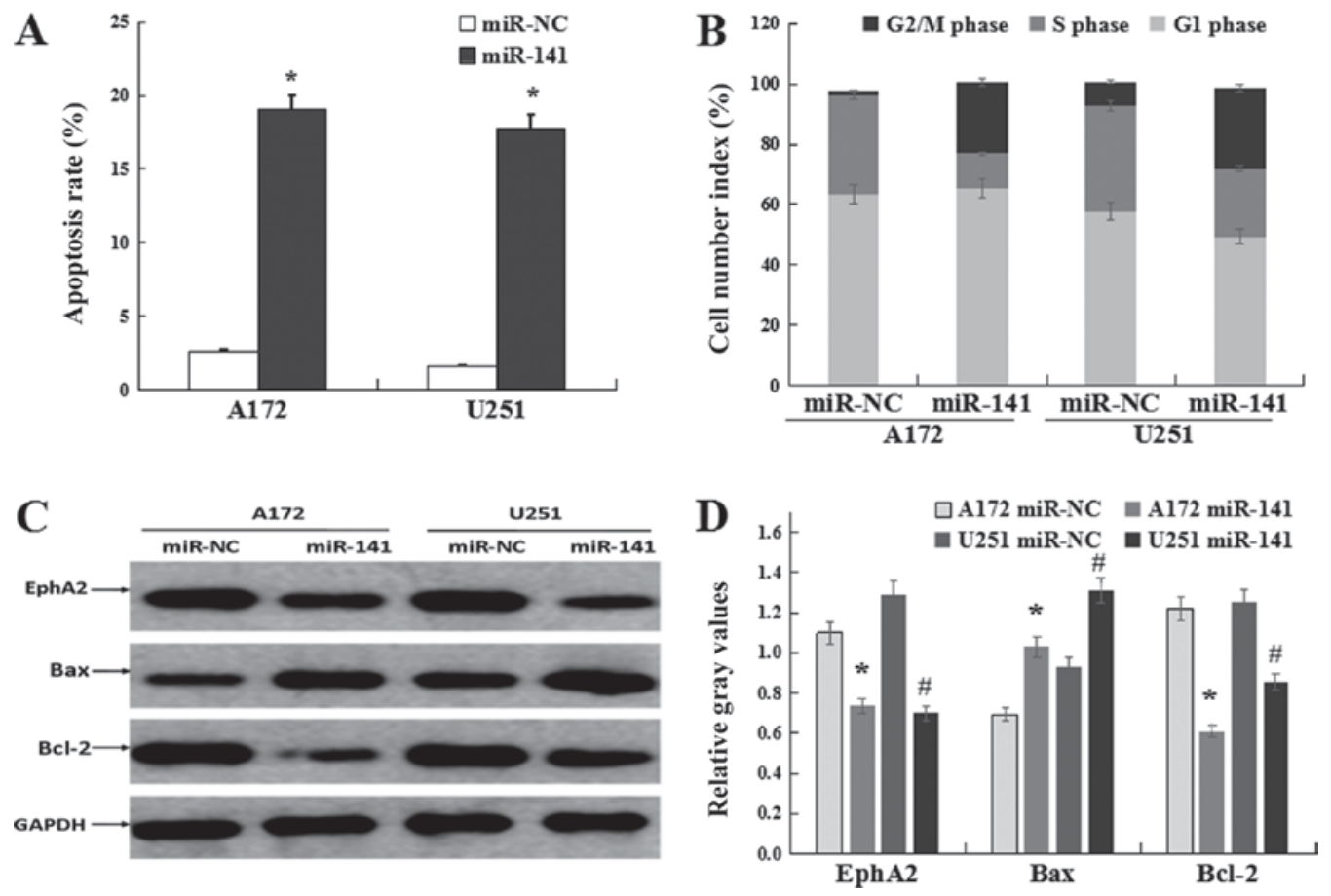

Figure 4. miR-141 induces apoptosis and cell cycle arrest in glioma-derived cells. A172 and U251 cells were transfected with miR-141 mimics or miR-NC control mimics. (A) miR-141 induces glioma-derived cell apoptosis. " $\mathrm{P}<0.05$ vs. miR-NC. (B) Cell cycle arrest at the G2/M phase. (C) Western blotting analysis of EphA2, Bax and Bcl-2 expression. (D) Gray scale analyses of the relative expression of EphA2, Bax and Bcl-2 in A172 and U251 cells. The data are presented as mean \pm standard error mean $(\mathrm{n}=3)$. Each bar represents the mean of three independent experiments performed in triplicate. ${ }^{*} \mathrm{P}<0.05$ vs. A172 miR-NC group; "P<0.05 vs. U257 miR-NC group. miR, microRNA; NC, negative control; EphA2, Ephrin type-A receptor 2; Bcl-2, B-cell lymphoma 2; Bax, Bcl-2-associated X protein.

\section{A EphA2-WT 5'-CCAAGAATACTTGAAGAAACAGAGTGGCCT-3' | IIIIII | miR-141 3'-AGGUUGUGACAUGACCUUCUAU-5'}

EphA2-Mut 5'-CCAAGAATACCGAGCTGGCCAGAGTGGCCT-3'

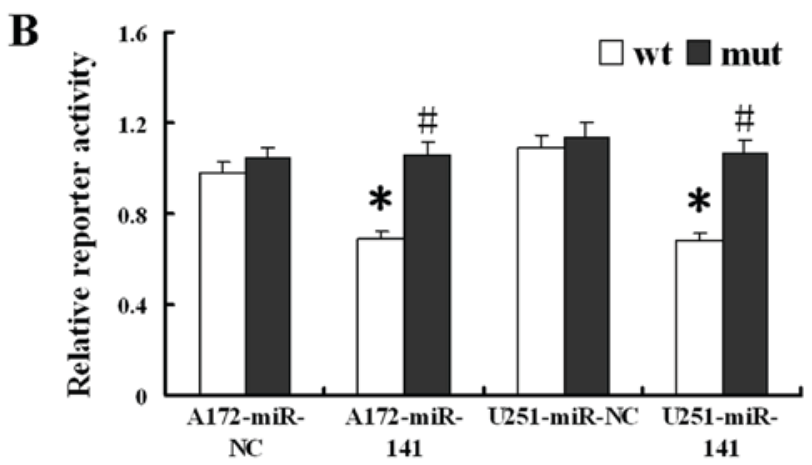

Figure 5. EphA2 is a direct target of miR-141. (A) Sequence alignment of the EphA2 3'UTR with wt and mut miR-141 target sites. (B) Luciferase reporter analysis of interactions between the 3'UTR of EphA2 and miR-141. The data are presented as mean \pm standard error mean $(n=3) .{ }^{*} \mathrm{P}<0.05$ vs. wt miR-NC group; ${ }^{~} \mathrm{P}<0.05$ vs. mut miR-NC group. miR, microRNA; NC, negative control; wt, wild-type; mut, mutant; EphA2, Ephrin type-A receptor 2; 3'UTR, 3' untranslated region.

that EphA2 may serve as a miR-141 target in glioma cells. This hypothesis was subsequently confirmed using dual luciferase assays. EphA2, a transmembrane Eph tyrosine kinase receptor, has been reported to have an important effect on the development of a variety of tumors (20). EphA2 has frequently been found to be over-expression and/or deregulation in advanced cancers, including malignant gliomas $(16,21)$, and accumulating evidence indicates that the increased expression of EphA2 may promote cancer progression by inducing its growth and invasion $(22,23)$. Additional analyses of EphA2 knockout mice have revealed a deficiency ability to support the implanted tumors' invasion and metastasis (24).

Accumulating evidence indicates that miRNAs may have key effect on both initiation and progression of tumor (25). In gastric cancer, miR-141 was decreased, and inhibited gastric cancer cell proliferation, colony formation, migration and invasion $(26,27)$. The miR-141's overexpression has been shown to depress the pancreatic cancer's invasion and migration, also include breast cancer and so on $(28,29)$. Numerous of reports have shown that miRNAs could regulate tumor progression through various signaling or target proteins. In hepatocellular carcinoma, Liu et al (30) found that miR-141 could suppress the HCC cells' migration and invasion by targeting Tiam1. In glioma, Peng et al (31) found that miR-141 was a tumor inhibitor by targeting TGF- $\beta 2$. Furthermore, the miR-141's expression patterns and levels were different in various tumor types. It's found in ovarian carcinoma (32), colorectal carcinoma (33) that miR-141 was up regulation; while it's down-regulated in breast cancer (29) and gastric cancer (26). These opposing findings indicated that miR-141 might play different roles in different cancer types as an oncogene or a tumor suppressor gene. In the present study, we found that exogenous miR-141 overexpression results in a dramatic suppression of glioma-derived cell proliferation, migration, invasion and VM formation, and an increase in 
$\mathbf{A}$
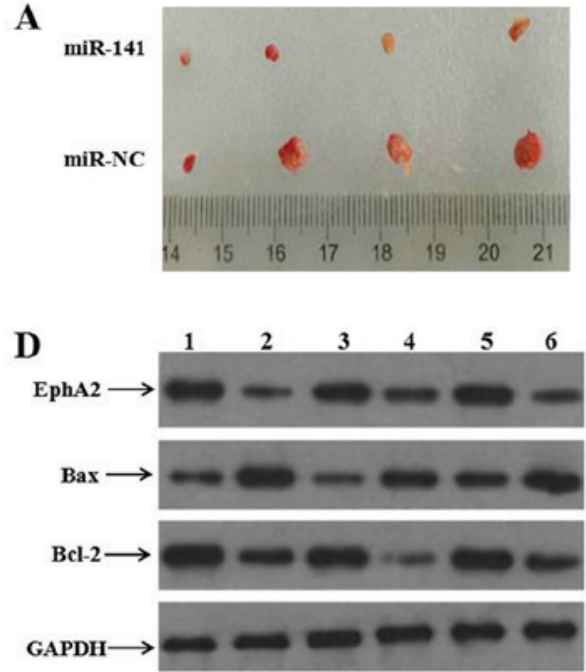

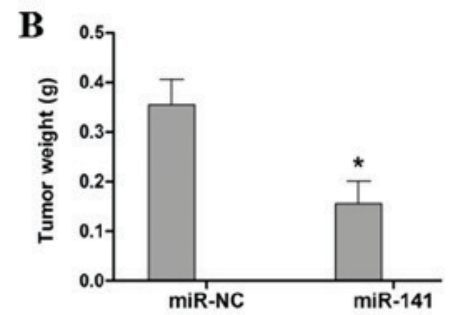

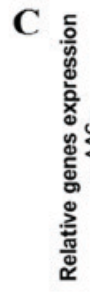
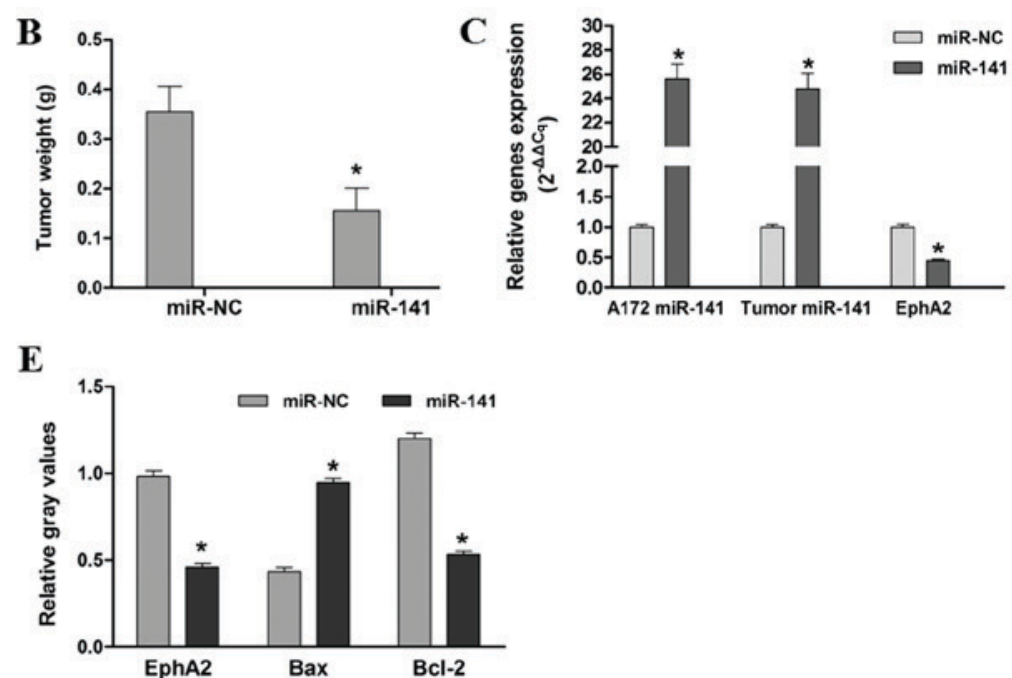

Figure 6. miR-141 suppresses tumorigenesis in vivo. (A) Macroscopic appearance of xenotransplanted tumors. (B) Quantitative analyses of tumor weights. (C) Expression of miR-141 in stably transfected A172 cells, and expression of miR-141 and EphA2 in glioma tumor tissues. (D) miR-141 suppresses EphA2 expression and induces glioma-derived cell apoptosis in vivo. Lanes 1, 3 and 5 are the miR-NC group; lanes, 2, 4 and 6 are the miR-141 group. (E) Gray scale analyses of the relative EphA2, Bax and Bcl-2 expression levels. The data are presented as mean \pm standard error mean $(n=3)$. Each bar represents the mean of three independent experiments performed in triplicate. "P<0.05 vs. miR-NC group. miR, microRNA; NC, negative control; EphA2, Ephrin type-A receptor 2; Bcl-2, B-cell lymphoma 2; Bax, Bcl-2-associated X protein.

$\mathbf{A}$

MiR-NC-PAS

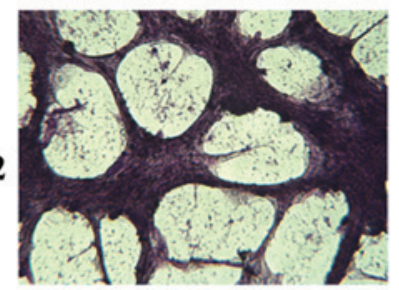

U251

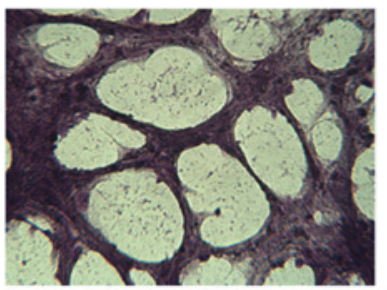

B

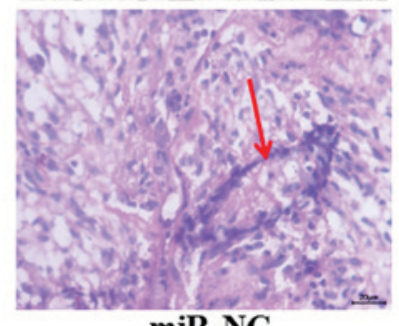

miR-NC
miR-141
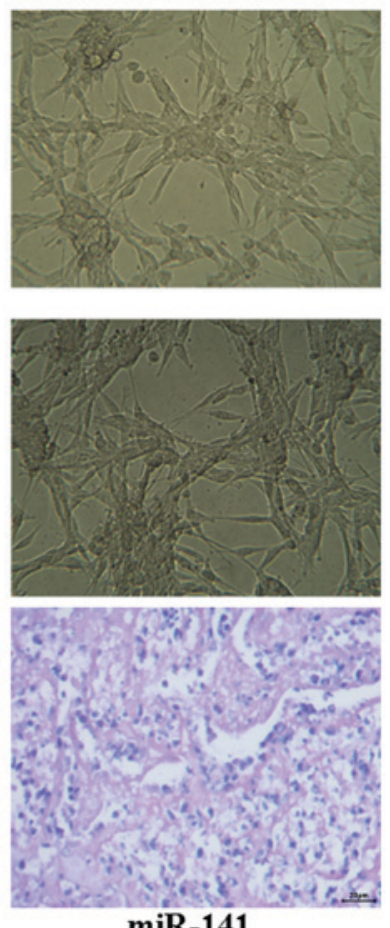

miR-141
Figure 7. miR-141 suppresses the development of VM in vitro and in vivo. (A) PAS staining of networks formed by A172 and U251 cells in the miR-NC control mimic and miR-141 mimic transfected groups respectively (magnification, $\mathrm{x} 400$ ). (B) PAS staining of tumor tissues, VM vessels formation by A172 cells in vivo. Following transfection with the miR-141 mimic, network formation was assessed using an inverted microscope (scale bars, $20 \mu \mathrm{m}$ ). VM, vasculogenic mimicry; PAS, periodic acid-Schiff; miR, microRNA; $\mathrm{NC}$, negative control.

cell cycle arrest. Additional in vivo analyses indicated that exogenous miR-141 overexpression resulted in profound decreases in glioma tumor weight and concomitant increases in apoptosis. Therefore, we conclude that miR-141 is involved in regulating glioma tumor progression, and may act as an anti-oncogenic factor.

Undoubtedly, one tumor usually requires a blood supply to sustain growth. The tumor microcirculation has central and key effect on the tumor's hematogenous dissemination. The mechanisms by which tumors obtain their blood supply have attracted considerable attention in these years. And two distinctive VM types have been reported in tumors: the patterned matrix type in VM and the tubular type in VM, and human glioblastoma tissues could formed VM of the tubular type (34). In glioma, Liu X pointed out that VM channels correlated with the increasing malignancy and higher aggressiveness, which may provide a complementation to the tumor's blood supply, especially in less vascularized regions (35). The cancer cells with highly metastatic and aggressive are capable of forming highly patterned vascular channels with basement membrane stained PAS-positive (36). Thus it may provide a potential method for GBM treatment by exploring a new way to inhibit VM. In GBM cells, we found the typical VM channels structure (PAS-positive channels) in vivo, and overexpression of miR-141 could inhibit VM formation. The findings in our study suggest that miR-141 and EphA2 are potential targets against VM treatment.

In conclusion, the experimental results from us indicate that miR-141 plays a key and important role in progression of glioma tumor by modulating cell proliferation, apoptosis, migration, invasion and VM formation through controlling EphA2 expression. As such, miR-141 and its target EphA2 may serve as a specific biomarker for glioma diagnosis/prognosis and as a potential anti-VM therapeutic target. In this study, we elucidate the regulatory relationship between miR-141 and EphA2, and their effects on the proliferation, migration, invasion and VM in glioma, which provides a laboratory basis for the treatment of glioma. The other specific target genes that 
are involved in tumorigenesis and regulated by miR-141, which could be developed as drug-oriented targets in the future. Since individual miRNAs may regulate several different target genes (miRNAs) that affect carcinogenic processes in different ways, studies aimed at gathering more detailed information on the molecular and cellular mechanisms underlying the action of miR-141 and its targets are required.

\section{Acknowledgements}

Not applicable.

\section{Funding}

The present study was supported by grants from the Innovation of Science and Technology Committee of Shenzhen City (grant no. JCYJ20150402155418386), the Natural Science Foundation of China (grant nos. 81302177 and 81272806), the Natural Science Foundation of Guangdong Province, China (grant no. S2012010009088) and Medical Scientific Research Foundation of Guangdong Province, China (grant no. B2013246).

\section{Availability of data and materials}

All data generated or analyzed during this study are included in this published article.

\section{Authors' contributions}

GL and YK conceived and designed the experiments. GL and $\mathrm{MH}$ performed the experiments, and YC and YY collected and processed the clinical samples. XS analyzed the data, and GL wrote the paper. All authors read and approved the final manuscript.

\section{Ethics approval and consent to participate}

The Institutional Review Boards of Southern Medical University and Zhujiang Hospital approved the protocol used in the present study, and all procedures were performed in accordance with the ethical standards established in the Declaration of Helsinki. All patients provided written informed consent prior to the study.

\section{Consent for publication}

All patients provided written informed consent.

\section{Competing interests}

The authors declare that they have no competing interests.

\section{References}

1. Demuth T and Berens ME: Molecular mechanisms of glioma cell migration and invasion. J Neurooncol 70: 217-228, 2004.

2. Wen PY and Kesari S: Malignant gliomas in adults. N Engl J Med 359: 492-507, 2008.

3. Wu N, Zhao XZ, Liu M, Liu H, Yao W, Zhang Y, Cao S and Lin X: Role of microRNA-26b in glioma development and its mediated regulation on EphA2. PLoS One 6: e16264, 2011.
4. Tanase C, Albulescu R, Codrici E, Popescu ID, Mihai S, Enciu AM, Cruceru ML, Popa AC, Neagu AI, Necula LG, et al: Circulating biomarker panels for targeted therapy in brain tumors. Future Oncol 11: 511-524, 2015.

5. Cruceru ML, Enciu AM, Popa AC, Albulescu R, Neagu M, Tanase CP and Constantinescu SN: Signal transduction molecule patterns indicating potential glioblastoma therapy approaches. Onco Targets Ther 6: 1737-1749, 2013.

6. Song Y, Mu L, Han X, Li Q, Dong B, Li H and Liu X: MicroRNA-9 inhibits vasculogenic mimicry of glioma cell lines by suppressing Stathmin expression. J Neurooncol 115: 381-390, 2013.

7. Huang M, Ke Y, Sun X, Yu L, Yang Z, Zhang Y, Du M, Wang J, Liu X and Huang S: Mammalian target of rapamycin signaling is involved in the vasculogenic mimicry of glioma via hypoxia-inducible factor-1 $\alpha$. Oncol Rep 32: 1973-1980, 2014.

8. Mosch B, Pietzsch D and Pietzsch J: Irradiation affects cellular properties and Eph receptor expression in human melanoma cells. Cell Adh Migr 6: 113-125, 2012.

9. Lytle JR, Yario TA and Steitz JA: Target mRNAs are repressed as efficiently by microRNA-binding sites in the 5' UTR as in the 3' UTR. Proc Natl Acad Sci USA 104: 9667-9672, 2007.

10. Bouyssou JM, Manier S, Huynh D, Issa S, Roccaro AM and Ghobrial IM: Regulation of microRNAs in cancer metastasis. Biochim Biophys Acta 1845: 255-265, 2014.

11. Bandres E, Agirre X, Bitarte N, Ramirez N, Zarate R Roman-Gomez J, Prosper F and Garcia-Foncillas J: Epigenetic regulation of microRNA expression in colorectal cancer. Int J Cancer 125: 2737-2743, 2009.

12. Chen X, Wang X, Ruan A, Han W, Zhao Y, Lu X, Xiao P, Shi H, Wang R, Chen L, et al: miR-141 is a key regulator of renal cell carcinoma proliferation and metastasis by controlling EphA2 expression. Clin Cancer Res 20: 2617-2630, 2014.

13. Shimono Y, Zabala M, Cho RW, Lobo N, Dalerba P, Qian D, Diehn M, Liu H, Panula SP, Chiao E, et al: Downregulation of miRNA-200c links breast cancer stem cells with normal stem cells. Cell 138: 592-603, 2009.

14. Mateescu B, Batista L, Cardon M, Gruosso T, de Feraudy Y, Mariani O, Nicolas A, Meyniel JP, Cottu P, Sastre-Garau X and Mechta-Grigoriou F: miR-141 and miR-200a act on ovarian tumorigenesis by controlling oxidative stress response. Nat Med 17: 1627-1635, 2011.

15. Schickel R, Park SM, Murmann AE and Peter ME: miR-200c regulates induction of apoptosis through CD95 by targeting FAP-1. Mol Cell 38: 908-915, 2010.

16. Hatano M, Eguchi J, Tatsumi T, Kuwashima N, Dusak JE, Kinch MS, Pollack IF, Hamilton RL, Storkus WJ and Okada H: EphA2 as a glioma-associated antigen: A novel target for glioma vaccines. Neoplasi 7: 717-722, 2005.

17. Yang L, Zhao J, Zhou G, Wang Y, Li L, Yuan H, Nan X, Guan L and Pei X: The 9L(LUC)/Wistar rat glioma model is not suitable for immunotherapy. Neural Regen Res 7: 1406-1411, 2012.

18. Li XY, Zhao Y, Sun MG, Shi JF, Ju RJ, Zhang CX, Li XT, Zhao WY, Mu LM, Zeng F, et al: Multifunctional liposomes loaded with paclitaxel and artemether for treatment of invasive brain glioma. Biomaterials 35: 5591-5604, 2014.

19. Xiao F, Zuo Z, Cai G, Kang S, Gao X and Li T: miRecords: An integrated resource for microRNA-target interactions. Nucleic Acids Res 37 (Database Issue): D105-D110, 2009.

20. Ogawa K, Pasqualini R, Lindberg RA, Kain R, Freeman AL and Pasquale EB: The ephrin-A1 ligand and its receptor, EphA2, are expressed during tumor neovascularization. Oncogene 19: 6043-6052, 2000.

21. Jin Q, Li X and Cao P: EphA2 modulates radiosensitive of hepatocellular carcinoma cells via p38/mitogen-activated protein kinase-mediated signal pathways. Kaohsiung J Med Sci 31: 510-517, 2015.

22. Zelinski DP, Zantek ND, Stewart JC, Irizarry AR and Kinch MS: EphA2 overexpression causes tumorigenesis of mammary epithelial cells. Cancer Res 61: 2301-2306, 2001.

23. Shao Z, Zhang WF, Chen XM and Shang ZJ: Expression of EphA2 and VEGF in squamous cell carcinoma of the tongue: Correlation with the angiogenesis and clinical outcome. Oral Oncol 44: 1110-1117, 2008.

24. Brantley-Sieders DM, Fang WB, Hicks DJ, Zhuang G, Shyr Y and Chen J: Impaired tumor microenvironment in EphA2-deficient mice inhibits tumor angiogenesis and metastatic progression. FASEB J 19: 1884-1886, 2005.

25. Lu J, Getz G, Miska EA, Alvarez-Saavedra E, Lamb J, Peck D, Sweet-Cordero A, Ebert BL, Mak RH, Ferrando AA, et al: MicroRNA expression profiles classify human cancers. Nat 435: 834-838, 2005 
26. Chen B, Huang T, Jiang J, Lv L, Li H and Xia S: miR-141 suppresses proliferation and motility of gastric cancer cells by targeting HDGF. Mol Cell Biochem 388: 211-218, 2014.

27. Zhou X, Xia Y, Su J and Zhang G: Down-regulation of miR-141 induced by helicobacter pylori promotes the invasion of gastric cancer by targeting STAT4. Cell Physiol Biochem 33: 1003-1012, 2014.

28. Xu L, Li Q, Xu D, Wang Q, An Y, Du Q, Zhang J, Zhu Y and Miao Y: hsa-miR-141 downregulates TM4SF1 to inhibit pancreatic cancer cell invasion and migration. Int J Oncol 44: 459-466, 2014.

29. Neves R, Scheel C, Weinhold S, Honisch E, Iwaniuk KM Trompeter HI, Niederacher D, Wernet P, Santourlidis S and Uhrberg M: Role of DNA methylation in miR-200c/141 cluster silencing in invasive breast cancer cells. BMC Res Notes 3: 219, 2010.

30. Liu Y, Ding Y, Huang J, Wang S, Ni W, Guan J, Li Q, Zhang Y, Ding Y, Chen B and Chen L: MiR-141 suppresses the migration and invasion of HCC cells by targeting Tiam1. PLoS One 9: e88393, 2014.

31. Peng T, Zhang S, Li W, Fu S, Luan Y and Zuo L: MicroRNA-141 inhibits glioma cells growth and metastasis by targeting TGF- $\beta 2$. Am J Transl Res 8: 3513-3521, 2016.
32. Iorio MV, Visone R, Di Leva G, Donati V, Petrocca F, Casalini P, Taccioli C, Volinia S, Liu CG, Alder H, et al: MicroRNA signatures in human ovarian cancer. Cancer Res 67: 8699-8707, 2007.

33. Schetter AJ, Leung SY, Sohn JJ, Zanetti KA, Bowman ED, Yanaihara N, Yuen ST, Chan TL, Kwong DL, Au GK, et al: MicroRNA expression profiles associated with prognosis and therapeutic outcome in colon adenocarcinoma. JAMA 299: 425-436, 2008.

34. El Hallani S, Boisselier B, Peglion F, Rousseau A, Colin C, Idbaih A, Marie Y, Mokhtari K, Thomas JL, Eichmann A, et al: A new alternative mechanism in glioblastoma vascularization: Tubular vasculogenic mimicry. Brain 133: 973-982, 2010.

35. Liu XM, Zhang QP, Mu YG, Zhang XH, Sai K, Pang JC, Ng HK and Chen ZP: Clinical significance of vasculogenic mimicry in human gliomas. J Neurooncol 105: 173-179, 2011.

36. Folberg R, Hendrix MJ and Maniotis AJ: Vasculogenic mimicry and tumor angiogenesis. Am J Pathol 156: 361-381, 2000.

c) (i) (3) This work is licensed under a Creative Commons EY NG ND Attribution-NonCommercial-NoDerivatives 4.0 International (CC BY-NC-ND 4.0) License. 